
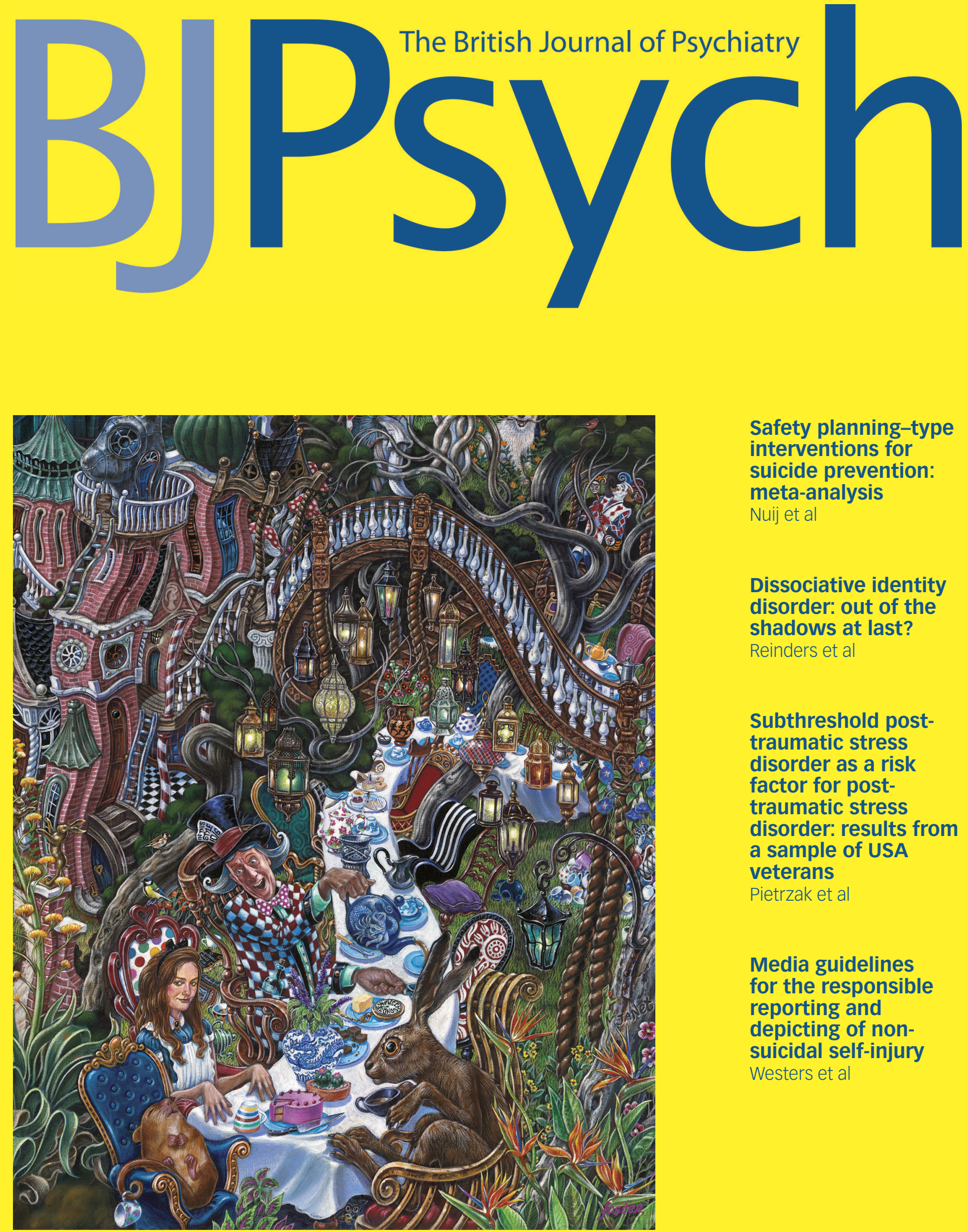

Safety planning-type interventions for suicide prevention: meta-analysis Nuij et al

Dissociative identity disorder: out of the shadows at last? Reinders et al

Subthreshold posttraumatic stress disorder as a risk factor for posttraumatic stress disorder: results from a sample of USA veterans Pietrzak et al

Media guidelines for the responsible reporting and depicting of nonsuicidal self-injury Westers et al 


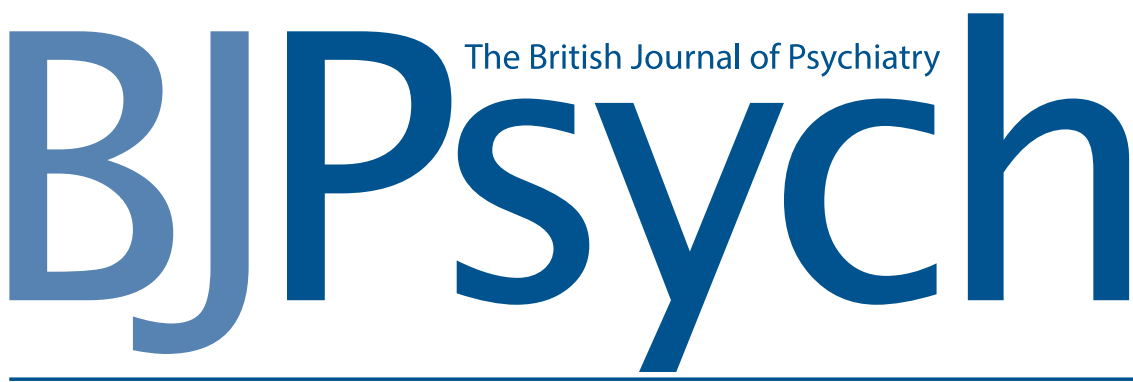

ISSN $0007-1250$

Editor Kamaldeep Bhui CBE
Patricia Casey (Ireland) Rakesh K Chadda (India) Andrew Cheng (Taiwan) Erika Comasco (Sweden) John Cookson (UK) Pim Cuijpers (The Netherlands) David Curtis (UK) Kimberlie Dean (Australia) Colin Drummond (UK) Emilio Fernandez Egea (UK) Sinan Guloksuz

(The Netherlands) Peter Haddad (UK) Judith Harrison (UK) Madelyn Hicks (USA) Cyrus Ho (Singapore) Louise Howard (UK) Khalida Ismail (UK) Navneet Kapur (UK) Eirini Karyotaki (The Netherlands) Kenneth Kaufman (USA) Steve Kisely (Australia) Ivan Koychev (UK) Rajeev Krishnadas (UK) Stephen Lawrie (UK)

Glyn Lewis (UK) Kwame McKenzie (Canada) Marco Mula (UK) Roger Mulder (New Zealand) Aileen O'Brien (UK) (Analysis Editor) Claire de Oliveira (UK) Martin Orrell (UK) Femi Oyebode (UK) (Book Reviews Editor) (Executive Contents Editor) Sarah Peters (UK) Michael Phillips (China) Mariana Pinto Da Costa (UK) Alexandra Pitman (UK) Rahul Rao (UK)
Frauke Schultze-Lutter (Germany) Sukhwinder Shergill (UK) Emily Simonoff (UK) Athula Sumathipala (UK) Eric Tan (Australia) Nori Takei (Japan) Derek Tracy (UK) (Editor for Public Engagement and Education)

Stuart Watson (UK) Richard Williams (UK) Kiriakos Xenitidis (UK) (Correspondence Editor) Allan Young (UK) Melvyn Zhang Weibin (Singapore) Yaara Zisman-Ilani (USA)

\section{Trainee Editors}

Katherine Adlington Angharad de Cates Laura McWhirter

\section{Statistical Advisors}

Eva Petkova

Min Yang

\section{Staff}

Head of Publishing

Elizabeth Hay

Managing Editor

Alice Shuttleworth

Senior Publications Coordinator Dianndra Roberts

\section{Past Editors}

Eliot Slater 1961-72 Edward H. Hare 1973-77 John L. Crammer 1978-83 Hugh L. Freeman 1984-93 Greg Wilkinson 1994-2003 Leila Tarokh (Switzerland)

(Analysis Editor) (Highlights Editor) Thomas Schulze (Germany)

Peter Tyrer 2003-13

Mary Cannon (Ireland)

The British Journal of Psychiatry is published monthly by the Royal College of Psychiatrists (a charity registered in England and Wales (228636) and in Scotland (SC038369)). The Journal publishes original work in all fields of psychiatry. Manuscripts for publication should be submitted online at https://mc.manuscriptcentral.com/bjpsych.

All papers in this journal are peer-reviewed. No person is permitted to take any role in the peer-review of a paper in which they have an interest, defined as follows: fees or grants from, employment by, consultancy for, shared ownership in, or any close relationship with, an organisation whose interests, financial or otherwise, may be affected by the publication of the paper.

\section{Subscriptions}

British Journal of Psychiatry (ISSN 0007-1250) is published monthly. The six issues starting January 2021 comprise Volume 218 , the six issues starting July 2021 comprise Volume 219. Orders from non-members of the College, which must be accompanied by payment, may be sent to any bookseller or subscription agent or direct to the publishers: Cambridge University Press, Journals Fulfilment Department, UPH, Shaftesbury Road, Cambridge CB2 8BS, UK, email journals@cambridge.org; or in the USA, Canada and Mexico, to Cambridge University Press, Journals Fulfilment Department, 1 Liberty Plaza, Floor 20, New York, NY 10006, USA, email subscriptions_newyork@cambridge.org. Japanese prices for institutions are available from Kinokuniya Company Ltd, P.O. Box 55, Chitose, Tokyo 156, Japan.

The annual subscription prices (including delivery by air but excluding VAT) for Volumes 218/219 are as follows:

\begin{tabular}{|lcc|}
\hline & INSTITUTIONS & INDIVIDUALS \\
\hline Print and online & $£ 589 / \$ 1049$ & $£ 475 / \$ 739$ \\
\hline Online only & $£ 483 / \$ 740$ & $£ 308 / \$ 481$ \\
\hline
\end{tabular}

Single issues are $f 57$ (US\$101 in the USA, Canada and Mexico) plus postage. EU subscribers (outside the UK) who are not registered for VAT should add VAT at their country's rate. VAT registered subscribers should provide their VAT registration number. Claims for missing issues should be made immediately on receipt of the subsequent issue.

Queries from college members about missing or faulty copies should be sent to Customer Services, Cambridge University Press, email journalS_societies@cambridge.org, tel. +44 (0)1223 326070.

\section{USPS ID Statement}

The British Journal of PSychiatry, ISSN 0007-1250, is published monthly by Cambridge University Press, UPH, Shaftesbury Road, Cambridge CB2 8BS, UK. The US annual subscription price is $\$ 976$ print and online/ $\$ 688$ online only for institutions and $\$ 687$ print and online/\$447 online only for individuals. Airfreight and mailing in the USA by agent named World Container Inc, 150-15, 183rd Street, Jamaica, NY 11413, USA. Periodicals postage paid at Brooklyn, NY 11256. US Postmaster: Send address changes to The British Journal of Psychiatry, World Container Inc, 150-15, 183rd Street, Jamaica, NY 11413, USA. Subscription records are maintained at Cambridge University Press, UPH, Shaftesbury Road, Cambridge CB2 8BS, UK. Air Business Ltd is acting as our mailing agent.

\section{Online access}

British Journal of Psychiatry is hosted on the Cambridge Core service at https://www.cambridge.org/core/journals/the-british-journal-ofpsychiatry.

Information about the College's publications is available at https://wmw. rcpsych.ac.uk.

Instructions to authors

Full instructions to authors are given at https://www.cambridge.org/core/ journals/the-british-journal-of-psychiatry/information/instructionscontributors.

\section{Advertising}

Correspondence and copy should be addressed to:

Stephen H. P. Mell, Advertising Manager, PTM Publishers Ltd, 41 Hart Close, Uckfield, East Sussex TN22 2DA, UK (email advertising@ptmpublishers. com; tel. 02086420162

Founded by J. C. Bucknill in 1853 as the Asylum Journal and known as the Journal of Mental Science from 1858 to 1963.

(OThe Royal College of Psychiatrists 2021. Unless so stated, material in the British Journal of Psychiatry does not necessarily reflect the views of the Editor or the Royal College of Psychiatrists. The publishers are not responsible for any error of omission or fact.

Printed in Great Britain by Henry Ling Limited, The Dorset Press, Dorchester, Dorset DT1 1HD.

This journal issue has been printed on FSCTM-certified paper and cover board. FSC is an independent, non-governmental, not-for-profit organization established to promote the responsible management of the world's forests. Please see www.fsc.org for information. 


\section{BJPsych}

\section{Contents}

A29 Editorial Board

A31 Highlights of this issue

\section{Editorials}

413 Dissociative identity disorder: out of the shadows at last? Antje A. T. S. Reinders and Dick J. Veltman

415 Media guidelines for the responsible reporting and depicting of non-suicidal self-injury

Nicholas J. Westers, Stephen P. Lewis, Janis Whitlock, Heather T.

Schatten, Brooke Ammerman, Margaret S. Andover and Elizabeth E. Lloyd-Richardson

\section{Review}

419 Safety planning-type interventions for suicide prevention: meta-analysis

Chani Nuij, Wouter van Ballegooijen, Derek de Beurs, Dilfa Juniar, Annette Erlangsen, Gwendolyn Portzky, Rory C. O'Connor,

Johannes H. Smit, Ad Kerkhof and Heleen Riper

\section{Paper}

427 Efficacy of the Zero Suicide framework in reducing recurrent suicide attempts: cross-sectional and time-to-recurrent-event analyses

Nicolas J. C. Stapelberg, Jerneja Sveticic, lan Hughes, Alice AlmeidaCrasto, Taralina Gaee-Atefi, Neeraj Gill, Diana Grice, Ravikumar Krishnaiah, Luke Lindsay, Carla Patist, Heidy Van Engelen, Sarah Walker, Matthew Welch, Sabine Woerwag-Mehta and Kathryn Turner

\section{Short Report}

437 Psychological distress, self-harm and attempted suicide in UK 17-year olds: prevalence and sociodemographic inequalities

Praveetha Patalay and Emla Fitzsimons

\section{Papers}

440 Using machine learning to predict suicide in the $\mathbf{3 0}$ days after discharge from psychiatric hospital in Denmark

Tammy Jiang, Anthony J. Rosellini, Erzsébet Horváth-Puhó,

Brian Shiner, Amy E. Street, Timothy L. Lash, Henrik T. Sørensen and Jaimie L. Gradus

447 psychiatry in history - Meduna's Mixture: surreal ecstasy or perplexing abreaction Jack Wellington, Alexander Wellington and Grace Wellington
448 Unravelling the contribution of complex trauma to psychopathology and cognitive deficits: a cohort study Stephanie J. Lewis, Karestan C. Koenen, Antony Ambler, Louise Arseneault, Avshalom Caspi, Helen L. Fisher, Terrie E. Moffitt and Andrea Danese

\section{Short Report}

456 Subthreshold post-traumatic stress disorder as a risk factor for post-traumatic stress disorder: results from a sample of USA veterans

Robert H. Pietrzak, Frances G. Javier, John H. Krystal and Steven M. Southwick

459 psychiatry in literature - Epidemics: A Journal of the Plague Year, London, 1665 - by Daniel Defoe Greg Wilkinson

460 psychiatry in pictures - Hugh Diamond, the father of psychiatric photography Sara Wetzler

\section{Columns}

462 Correspondence

464 Ten books

467 Book Review

468 Contents of BJPsych Advances

469 Kaleidoscope

\section{Cover picture}

Wonderland (detail), 2020

(c) Graham Foster

This cover is a small detail taken from a large commissioned Alice in Wonderland painting depicting the Mad Hatter's tea party. I enjoy painting in a somewhat surreal style, so the dreamlike, almost hallucinogenic qualities of the story really appealed. The recent advancement of therapy involving various hallucinogens such as psilocybin seems to tie in well with this painting!

Website: www.grahamfoster.com Instagram/Facebook: Graham Foster Art

We are always looking for interesting and visually appealing images for the cover of the Journal and would welcome suggestions or pictures, which should be sent to Dr Allan Beveridge, British Journal of Psychiatry, 21 Prescot Street, London, E1 8BB, UK or bjp@rcpsych.ac.uk. 